\title{
A rare clinical presentation of Ebstein-Barr virus
}

\begin{abstract}
In this letter we report a case of Guillain-Barré syndrome associated with infectious mononucleosis. A 20-year-old woman presented to our hospital with weakness of legs and arms. She had felt weakness in her legs for three days and in arms for one day. She had one week history of pharyingitis, muscle pain, and fever. Serological data confirmed infectious mononucleosis. Electrophysiological findings and cerebrospinal fluid examinations confirmed Guillain-Barré syndrome. She was treated with immunoglobulin, methylprednisolone and acyclovir. Paresis improved five days after the end of immunoglobulin therapy. Ebstein-Barr virus infection and infectious mononucleosis must be considered among patients with Guillain-Barré syndrome.
\end{abstract}

Keywords: Guillain-Barré syndrome, infectious mononucleosis.

[Braz J Infect Dis 2010;14(2):211-212] OElsevier Editora Ltda.

\section{TO THE EDITOR}

A 20-year old woman admitted to our hospital reporting weakness, which had begun three days ago at her legs. She also reported weakness at her arms, which started one day ago. She had one week history of pharyingitis, muscle pain, and fever around $38^{\circ} \mathrm{C}$.

Neurological examination revealed paresis of (Medical Research Council) MRC grade 3-4, with absent deep tendon reflexes. Cerebrospinal fluid revealed increased protein $80 \mathrm{mg} / \mathrm{dL}(15-45 \mathrm{mg} / \mathrm{dL})$ with $10 / \mathrm{mm}^{3}$ leukocytes and a glucose level of $52 \mathrm{mg} / \mathrm{dL}$ (40-70 mg/dL). Electrodiagnostic studies were performed on days 4 and 11 of weakness. Absent $\mathrm{F}$ waves and normal motor latencies were observed. Concurrent neurological findings, results of cerebrospinal fluid analysis, and nerve conduction studies were compatible with axonal form of Guillain-Barré syndrome (GBS). Bacterial cultures were negative. Complete blood count, serum electrolytes, and renal function tests were normal. Aspartate transaminase was $96 \mathrm{IU} / \mathrm{L}(5-35 \mathrm{IU} / \mathrm{L})$ and alanine transaminase $104 \mathrm{IU} / \mathrm{L}(0-55 \mathrm{IU} / \mathrm{L})$. Urinary excretion of porphyrins was normal. Serologic tests for HIV, VDRL, CMV, HSV, hepatitis A, hepatitis B, hepatitis C, b Borrelia, and Brucella were all negative. VCA-IgM and VCA IgG were positive. Anti EBNA IgM was negative, Anti EA-D IgG was positive. Also serological data confirmed infectious mononucleosis (IM). She was treated for GBS and IM with immunoglobulin IV $0.4 \mathrm{~g} / \mathrm{kg} / \mathrm{d}$ for 5 days, methylprednisolone IV $1 \mathrm{~g}$ for 3 days, and acyclovir IV $750 \mathrm{mg}$ q8h for 2 weeks. Paresis improved 5 days after the end of immunoglobulin therapy, but facial paresis did not recovered.

Ebstein-Barr virus (EBV) infects more than $98 \%$ of world's adult population, primary EBV infection occurs usually during childhood. EBV enters the body by infecting epithelial cells in the oropharynx. IM is a primary clinical syndrome of EBV, which occurs with fever, pharyingitis, fatigue, lymphadenopathy, splenomegaly, and elevated liver functional tests. ${ }^{1}$ Most IM is a self limited disease, but it could cause many systemic complications, such as cardiac, renal, hepatic, hematological, immunological, respiratory, and neurological. Neurological complications account for $2-5 \%$ of patients. ${ }^{2,3}$ The most seen neurological complications of IM are encephalitis, meningitis, GBS with the involvement of cranial nerves, cerebellitis, myelitis, and cranial neuropathies. As we know, the clinical picture of GBS is usually a generalized polyradiculoneuropathy affecting limbs proximally and distally and commonly spreading to involve facial and other cranial nerves. ${ }^{2,3}$
Author

Çagatay Öncel

MD - Department of

Neurology Pamukkale

- University Faculty of

Medicine Denizli-Turkey.
Submitted on: 01/21/2009 Approved on: 05/31/2009

Correspondence to: Hastane cad. No. 26 Denizli - Turkey Phone: 00902582612673 Fax: 00902582423512 E-mail: cagatayoncel@ yahoo.com 
Although the effect of methylprednisolone and acyclovir treatment in IM and GBS has not been investigated in randomized studies, patients treated with corticosteroids and acyclovir seem to be improved. ${ }^{2,4}$ In our case, paresis improved five days after the end of immunoglobulin therapy, but facial paresis did not recovered.

As a conclusion, the present case indicates that EBV infection that causes IM must be considered among the possible causes in patients with GBS.

\section{REFERENCES}

1. Straus SE, Cohen JI, Tosato G, Meier J. NIH conference. Epstein-Barr virus infections: biology, pathogenesis, and management. Ann Intern Med 1993; 118(1):45-58.

2. Majid A, Galetta SL, Sweeney CJ et al. Epstein-Barr virus myeloradiculitis and encephalomyeloradiculitis. Brain 2002; 125:159-65.

3. Jenson HB. Acute complications of Epstein-Barr virus infectious mononucleosis. Curr Opin Pediatr 2000; 12(3):263-8.

4. Finsterer J. Treatment of immune-mediated, dysimmune neuropathies. Acta Neurol Scand 2005; 112(2):115-25. 